\title{
La política de la prostitución: el papel del movimiento de mujeres y los organismos de igualdad en España ${ }^{1}$
}

\author{
Celia Valiente Fernández \\ Universidad Carlos III de Madrid \\ valiente@polsoc.uc3m.es
}

RESUMEN

Desde mediados de los años sesenta la política de la prostitución en España fue fundamentalmente abolicionista, pues el ordenamiento jurídico no definía el ejercicio de la prostitución como un delito, pero sí muchos comportamientos en este ámbito, tales como organizar la ajena o lucrarse con ella. Desde 1995 el Estado central ha despenalizado casi todas las conductas relativas a la prostitución, y ha centrado esta política pública en la lucha contra el tráfico de personas para su explotación sexual. Este artículo documenta el modesto papel desempeñado por el movimiento organizado de mujeres y los organismos de igualdad en la elaboración de la principal legislación sobre la prostitución en el período postfranquista, e identifica dos razones para explicar esta escasa intervención: la débil prioridad otorgada a la prostitución por el feminismo societal e institucional (tomados en su conjunto) y la baja permeabilidad de la arena política parlamentaria a la influencia de actores externos.

Palabras clave: Prostitución, Movimiento de Mujeres, Feminismo de Estado, España, Política.

\footnotetext{
1 El origen de este artículo es parte de mi contribución a un proyecto internacional de investigación sobre la influencia del movimiento organizado de mujeres y los organismos de igualdad en los debates políticos acerca de cuestiones que han adquirido importancia política en democracias postindustriales, dirigido por Dorothy McBride Stetson y Amy G. Mazur. El diseño del estudio puede consultarse en www.fau.edu/divdept/schmidt/rngs. Agradezco a Manuel Jiménez sus valiosos comentarios a versiones anteriores de este trabajo, que fueron presentadas en congresos en España y Estados Unidos; una de ellas será publicada en inglés en el libro The Politics of Prostitution: Women's Movements, Democratic States and the Globalization of Sex Work (ed. Joyce Outshoorn, Cambridge University Press).
} 


\section{INTRODUCCIÓN}

La intervención del Estado central en el área de política pública relativa a la prostitución ha sido históricamente variada en España. Por ejemplo, en 1935, durante la II República, las autoridades la prohibieron (Decreto de 28 de junio), siendo esta interdicción suprimida en 1941 (Decreto de 27 de marzo). El 18 de junio de 1962 nuestro país ratificó la Convención para la Represión de la Trata de Personas y de la Prostitución Ajena de Naciones Unidas de 1949, de carácter claramente abolicionista, modificándose en 1963 el Código Penal de acuerdo con dicha Convención. Además de la no penalización de la prostitución (pero sí de muchos de los comportamientos que la rodean), en términos teóricos, la perspectiva abolicionista conceptualiza la prostitución como un ataque a la dignidad de las personas, por lo que es irrelevante que quienes desarrollan esta actividad lo hagan voluntariamente ${ }^{2}$. El abolicionismo también defiende que el Estado y la sociedad realicen serios esfuerzos para ayudar a las prostitutas a que dejen de serlo. El ordenamiento jurídico español desde 1963 no definía como delincuentes a las prostitutas, pero sí a quienes promovían la prostitución de otros o se beneficiaban de ella, pudiendo ser castigados con penas de prisión de hasta seis años (Carracedo Bullido, 2001: 151-154). Ello no obstante, el abolicionismo de la España de entonces era imperfecto, pues la Ley 16/1970, de 4 de agosto, sobre peligrosidad y rehabilitación social, consideraba a las prostitutas, junto con otros tipos de personas, individuos peligrosos para la sociedad. En consecuencia, podían ser confinadas en centros especiales o castigadas con el exilio interior, al residir en los jueces la potestad de prohibirles habitar en determinados lugares.

La (imperfecta) legislación abolicionista no cambió con la transición a la democracia. Por contraste, en 1995 España se alejó decididamente de su pasado abolicionista al despenalizar muchos comportamientos asociados a la prostitución, tales como organizar la ajena o lucrarse con ella (excepto en el caso de la ejercida por menores e incapaces). Reformas legales ulteriores centraron progresivamente la política de la prostitución en la lucha contra el tráfico de personas con el propósito de su explotación sexual. Este artículo documenta el modesto papel desempeñado por el movimiento organizado de mujeres y el principal organismo de igualdad del Estado central, el Instituto de la Mujer, en el área de política pública relativa a la prostitución, e indaga acerca de las razones que explican esta escasa intervención ${ }^{3}$.

\footnotetext{
${ }^{2}$ La mayoría de las personas que ejercen la prostitución son mujeres, por lo que a partir de ahora me referiré a ellas utilizando el femenino.

3 Las investigaciones sobre movimientos de mujeres y organismos de igualdad, entre ellas ésta, tienden a presentarlos como actores unitarios, cuando en realidad no lo son. Además, son proclives a describir los movimientos como si de seres animados se tratara, por ejemplo, cuando afirman que «el movimiento $X$ defendió la postura A», o «el organismo Y apoyó la política pública B». Conviene recordar que este tipo de expresiones constituyen recursos estilísticos, ya que sólo las personas pueden defender posturas o apoyar políticas públicas.
} 


\section{MARCO ANALÍTICO}

En las últimas décadas se han realizado en el mundo occidental numerosos estudios sobre el movimiento organizado de mujeres, que han investigado acerca de sus orígenes, sus objetivos, sus estructuras organizativas, su repertorio de actividades, sus aliados políticos y su éxito o fracaso. La mayoría de los análisis sobre la impronta de este movimiento en las políticas públicas han analizado el contenido de las mismas, y han tratado de valorar hasta qué punto las medidas estatales han hecho suyas las prioridades del movimiento (por ejemplo: Banaszak, 1996; Bashevkin, 1996; Beckwith, 1987; Gelb, 1987, 1989). Este modo de inquirir acerca del posible influjo de la movilización feminista resulta acertado, si tenemos en cuenta que un sector del movimiento se propone influir decisivamente en los fundamentos de las actuaciones estatales.

Se han publicado, asimismo, trabajos académicos sobre el llamado «feminismo de Estado», «feminismo oficial» o «feminismo institucional». Estas expresiones designan el conjunto de instituciones $u$ organismos de igualdad que en los países occidentales (y también no occidentales) se han fundado, desde aproximadamente los años setenta, con el mandato explícito de mejorar la situación de las mujeres en su conjunto (como quiera que se defina esta mejora) (Dahlerup, 1993; Duerst-Lahti, 1989; Eisenstein, 1991; Ferree, 1991-1992; Franzway, Court y Connell, 1989; Kamenitsa, 1997; Outshoorn, 1997; Sawer, 1990; Stetson y Mazur, 1995; Stewart ,1980; Watson, 1990).

Los análisis sobre el feminismo oficial también han examinado el proceso de su fundación, sus metas, sus procedimientos para alcanzarlas, sus características organizativas y el posible impacto de estas instituciones principalmente sobre el contenido de las políticas públicas. Esta forma de escrutar el influjo del feminismo oficial es adecuada, ya que dichas instituciones no poseen las competencias necesarias para elaborar, ellas mismas, medidas de igualdad, pero entre sus funciones se encuentra la de intentar persuadir a otras para que lleven a cabo tales actuaciones. Por ejemplo, un organismo feminista puede considerar que existen serios déficits de equidad entre los hombres y las mujeres en el sistema educativo. Tratará de convencer a las autoridades educativas para que pongan en práctica acciones de igualdad, puesto que son ellas, y no la institución feminista, quienes tienen poderes en el ámbito educacional.

Hasta la fecha se han realizado muy pocos intentos sistemáticos de estudiar, a la vez, la influencia del movimiento organizado de mujeres y del feminismo oficial en diversas áreas de política pública (pero véanse Mazur, 2001; Stetson, 2001; Stetson y Mazur, 2000). Sorprende esta ausencia de análisis conjunto, dado que en algunos países este movimiento asociativo (o alguna corriente encuadrada en el mismo) reivindicó la fundación de estas institu- 
ciones, y los decisores políticos terminaron creándolas en parte intentando satisfacer estas demandas provenientes de un sector organizado de la sociedad. Además, tanto el movimiento como los organismos feministas persiguen, si bien por medios distintos, el mismo objetivo: la erosión de la subordinación de las mujeres como grupo. Parece, pues, perentorio analizar el impacto de ambos actores sociales y políticos sobre la actuación del Estado.

Los trabajos acerca de los logros (o las derrotas) de los movimientos sociales en general son aún notablemente más escasos que los estudios sobre otras dimensiones de la acción colectiva. Varias son las razones que pueden aducirse para explicar este déficit de investigación, entre otras, la dificultad teórica para definir el «éxito» y el «fracaso» de los movimientos sociales, o los obstáculos metodológicos que surgen a la hora de diferenciar su impacto de los efectos causados por otros factores (Burnstein, Einwhoner y Hollander, 1995; Gamson, 1990; Giugni, 1998; Giugni, McAdam y Tilly, 1999; Rochon y Mazmanian, 1993). La investigación sobre los resultados de la movilización social constituye, pues, una tarea pendiente.

La influencia sobre el contenido de las políticas públicas no constituye la única impronta posible del movimiento y las instituciones a favor del estatus de las mujeres en el ámbito de la toma de decisiones estatales. La literatura general sobre movimientos sociales propone que éstos tratan de ocasionar el cambio social en un sentido más amplio (McAdam, McCarthy y Zald, 1988: 727). Mantiene que el impacto de los movimientos comprende varias dimensiones, además de su capacidad para modificar el contenido de las decisiones gubernamentales. Entre las consecuencias de la movilización social destaco ahora la transformación del discurso político y el debate público. En el caso del movimiento de mujeres y del feminismo oficial, este segundo tipo de ascendiente está mucho menos estudiado por las ciencias sociales. Defiendo que centremos la atención también en esta clase de impronta, ya que, según la investigación internacional sobre políticas públicas, para que se establezca una de ellas es necesario que los decisores estatales conceptualicen una situación como un problema que requiere la intervención gubernamental. Además, el modo de definir los problemas en la esfera política determina parcialmente cómo van a ser resueltos (Cobb y Elder, 1972: 30; Crenson, 1971; Dery, 1984: 16-17; Kingdom, 1984: 207; Nelson, 1984: 13, 23; Schattshneider, 1975 [1960]).

Las decisiones estatales son normalmente precedidas por debates en los que se barajan distintas maneras de definir los problemas que captan la atención de los gobernantes y las diferentes soluciones posibles; en ellos pueden, en teoría, participar las asociaciones de mujeres y los organismos de igualdad. Si ambos toman parte en estas deliberaciones, es razonable argumentar que tal vez ejerzan cierta influencia en el proceso de toma de decisiones políticas. 
Sostengo que el movimiento de mujeres y las instituciones feministas desempeñan un papel importante en el proceso político cuando consiguen introducir referencias al género en las discusiones que allí tienen lugar. Utilizo el término "género» para referirme a las diferencias entre los hombres y las mujeres relativas a su situación económica, política, social y cultural, si bien soy consciente de que el vocablo tiene muchos significados (Scott, 1986; Hood-Williams, 1996). Cuando el movimiento y/o los organismos logran incluir nociones de género en un debate público, los participantes en el mismo las utilizan en sus argumentaciones, por ejemplo, describiendo cómo los problemas afectan de manera distinta a hombres y a mujeres, o identificando qué soluciones favorecen más a unos que a otras (o viceversa). Propongo que, a igualdad de otras condiciones, si la deliberación que precede a una política contiene menciones al género, la política en cuestión responderá mejor a las necesidades de las mujeres que si no las contuviera.

Todas las discusiones políticas pueden comprender conceptos de género. Si bien el sentido común nos indica que es más fácil insertar la perspectiva de género en algunas discusiones que en otras, ningún tema está necesariamente relacionado de forma automática con el estatus de las mujeres en las deliberaciones gubernamentales. Permítaseme ilustrar esta proposición con el ejemplo de la interrupción voluntaria del embarazo. Puede tal vez resultar obvio, a primera vista, concebir este asunto como una cuestión que concierne a las mujeres, puesto que los abortos se efectúan cuando los embriones o los fetos se encuentran en sus organismos. Cabe pensar entonces que sería relativamente sencillo incorporar menciones al género en una discusión sobre el tema. Ello no obstante, no siempre sucede así y, en ocasiones, algunos debates acerca de la finalización voluntaria del embarazo tratan sobre todo (o exclusivamente) de los derechos del embrión y/o del feto y de los médicos, y prácticamente nada (o nada en absoluto) de los de las mujeres.

Una última apreciación es necesaria ahora. Una parte de la literatura sobre políticas públicas propone la existencia de distintas comunidades políticas (policy communities) y modos de elaborar medidas en torno a diferentes asuntos, más que (o al igual que) la de un estilo nacional de hacer política (policy style) peculiar de cada país (Feick, 1992; Harrop, 1992; Hayward, 1991; Heclo, 1978; Heidenheimer, Heclo y Adams, 1990). De esta propuesta se desprende que, en el mismo Estado e incluso en el mismo período temporal, el movimiento de mujeres y el feminismo institucional pueden ser actores influyentes en unas materias pero no en otras. Por ello, es preciso estudiar el impacto del feminismo societal y estatal no ya en términos generales y abstractos, sino en áreas concretas de decisión gubernamental.

En síntesis, puesto que en los países occidentales amplios sectores del movimiento de mujeres y el feminismo oficial comparten el objetivo de tratar de dejar su impronta en el ámbito político para que la actuación del Estado contribuya a limar las desigualdades en- 
tre las mujeres y los hombres, es preciso examinar el posible impacto de los dos actores. De otro lado, si bien las literaturas sobre movimientos de mujeres y organismos de igualdad han indagado acerca de su influjo sobre el contenido de las políticas públicas, también ha de analizarse el ascendiente de ambos sobre la deliberación pública que precede a las decisiones políticas. Este artículo emprende, a continuación, las dos tareas de investigación.

\section{SELECCIÓN DE LOS CASOS DE ESTUDIO Y FUENTES}

El período de estudio de este trabajo es la España postautoritaria (1975-2002), y el área de política pública escogida es la prostitución. Se trata de un asunto con una marcada dimensión de género por varias razones; ahora destaco, como he mencionado con anterioridad, que la mayor parte (si bien no la totalidad) de quienes la ejercen son mujeres, mientras que la abrumadora mayoría de los clientes (de prostitución femenina y masculina) son hombres.

La disposición legislativa más importante relativa a la prostitución es el Código Penal, que define algunos comportamientos en este ámbito (pero no la prostitución en sí) como delitos. En los últimos años, el fenómeno del creciente número de mujeres traficadas y obligadas a prostituirse ha convertido la Ley sobre derechos y libertades de los extranjeros en España y su integración social (de ahora en adelante, «Ley de extranjería») en el segundo instrumento de intervención en esta materia, si bien su relevancia es menor que la del Código Penal. Puesto que tanto éste como la Ley de extranjería se elaboran y reforman en las Cortes, esta institución domina esta arena de decisión pública.

Tres han sido las reformas legales más destacadas en la cuestión de que trata esta investigación. Primero, según he explicado antes, en 1995 se aprobó un nuevo Código Penal, el cual despenalizaba la mayor parte de los comportamientos asociados a la prostitución considerados delitos en el pasado (excepto en el caso de la prostitución de menores e incapaces), y suprimió la Ley sobre peligrosidad y rehabilitación social de 1970. Segundo, la reforma de este Código en 1999 definió un nuevo delito, el del tráfico de personas con el objeto de su explotación sexual, y aumentó las penas que castigaban los delitos relacionados con la prostitución de menores e incapaces y los cometidos por organizaciones criminales. Tercero, la Ley de extranjería de enero de 2000 ofrecía a las inmigrantes ilegales que habían sido traficadas y obligadas a prostituirse permisos de residencia y trabajo si denunciaban a sus traficantes y colaboraban en su persecución. Por su amplitud, la elaboración del Código en 1995 es, con diferencia, la reforma más importante de las tres mencionadas. 
En este artículo analizo los debates parlamentarios que precedieron a las tres medidas relativas a la prostitución más importantes desde 1975, prestando especial atención a la posible intervención en ellos del movimiento organizado de mujeres y del Instituto de la Mujer. El debate parlamentario es sólo una parte del debate político general. Centro mi atención únicamente en este componente de la deliberación pública debido a los constreñimientos de espacio y a la limitación de los recursos de investigación; dejo para el futuro el examen de otros ingredientes principales de la discusión, tales como el tratamiento de la prostitución por parte de los medios de comunicación o de los estudios académicos.

El movimiento organizado de mujeres se gestó en los años setenta, en el contexto de la oposición al régimen de Franco. Tras crecer entre 1975 y el principio de los años ochenta, inició un proceso de consolidación. En términos comparativos, se trata de un movimiento relativamente débil (pero no desdeñable), por su número modesto de militantes, la escasa repercusión de sus actividades en los medios de comunicación (con algunas excepciones) y su reducida capacidad para iniciar en solitario amplios debates en la sociedad. Ello no obstante, ha mostrado ciertos signos de fortaleza; entre otros, la organización de jornadas feministas a las que han asistido, dependiendo de la convocatoria, entre 3.000 y 5.000 mujeres $^{4}$.

Por lo que respecta al feminismo oficial, el Instituto de la Mujer (IM) fue creado en 1983. Se le encomendaron cinco amplias funciones: promover políticas de igualdad, evaluar su puesta en práctica, estudiar la situación de las mujeres en España, informarles de sus derechos, y recibir y canalizar denuncias de discriminación por razón de sexo. En términos comparativos internacionales, este organismo autónomo cuenta con una plantilla y un presupuesto relativamente elevados: en 1995 (año de la primera reforma legislativa estudiada en este trabajo), 2.659 millones de pesetas de prepuesto final y 139 personas en régimen de personal funcionario o laboral (Instituto de la Mujer, 1996a: 107-108, 114) ${ }^{5}$.

Las fuentes utilizadas para este trabajo incluyen los tres debates parlamentarios citados, legislación, documentos publicados de grupos del movimiento organizado de mujeres y del Instituto de la Mujer, entrevistas en profundidad semiestructuradas a un miembro del equipo directivo de este organismo de igualdad, y a integrantes de dicho movimiento asociativo y de otras organizaciones de la sociedad civil activas en materia de prostitución (listadas al final del artículo), además de dossiers de prensa.

\footnotetext{
4 Sobre el movimiento organizado de mujeres, prestando especial énfasis a su rama feminista, véanse, entre otros: Durán y Gallego (1986); Escario, Alberdi y López-Accotto (1996); Folguera (1988); Kaplan (1992); Scanlon (1976, 1990); Threlfall $(1985,1996)$.

5 Sobre el IM, véanse, entre otros: Threlfall (1996, 1998); Valiente Fernández (1996, 2000).
} 
A continuación presento el análisis de las tres deliberaciones mencionadas. Para cada una de ellas describo el marco general del debate, así como la medida en que el contenido de la decisión finalmente adoptada coincidió con las reivindicaciones del movimiento de mujeres y del feminismo oficial. También indago si estos dos actores consiguieron (o no) incluir nociones de género en la discusión parlamentaria.

\section{DEBATE 1: LA ELABORACIÓN DEL CÓDIGO PENAL DE 1995 (1994-1995)}

\section{El marco general del debate}

En 1994 el Gobierno del Partido Socialista Obrero Español (PSOE), en el poder entre 1982 y 1996, presentó un proyecto de reforma del Código Penal (el Código existente era una versión sustancialmente modificada del de 1848). Ese proyecto contenía algunas reformas en materia de prostitución. Excepto en el caso de la ejercida por menores e incapaces, despenalizaba la promoción de la prostitución, ajena así como la acción de lucrarse con ella. Segundo, penalizaba a quienes forzaran a otros a prostituirse. Este bosquejo de legislación, entonces, distinguía implícitamente entre la prostitución forzosa y la ejercida libremente (Carracedo Bullido, 2001: 155-157) y, de manera tácita, proponía que la misión de la ley penal habría de residir en combatir la primera modalidad pero no la segunda. Por último, abolía la Ley de 1970 sobre peligrosidad y rehabilitación social.

El debate parlamentario previo a la aprobación del Código Penal apenas contuvo referencias a la prostitución ${ }^{6}$. Los artículos sobre esta materia en dicha norma jurídica están incluidos en el Título VIII, sobre «Delitos contra la libertad sexual», del Libro II («Delitos y sus penas»). Cuando los diputados y senadores deliberaron acerca de este Título, debatieron otros asuntos, por ejemplo, las agresiones sexuales. Fueron presentadas muy pocas enmiendas sobre prostitución, proponiendo éstas modificaciones de escasa envergadura, que no pretendían cambiar sustancialmente el tratamiento dado a la materia por el proyecto gubernamental. El Partido Popular (PP), entonces en la oposición, manifestó en las Cortes albergar una especial preocupación por la protección de los menores ${ }^{7}$. Los comentarios acerca de la prostitución se hicieron mientras se debatían otros artículos que trataban sobre otras cuestiones, tales como la violación. EI PSOE alabó la legislación española por definir este delito con independencia de la profesión de las víctimas, de modo que cuando fueran prostitutas se perseguiría exactamente igual que en el caso de cualquier otra víctima. EI PSOE acusó al PP de no apoyar la po-

${ }^{6}$ Los trabajos parlamentarios relativos al establecimiento del Código pueden consultarse en Delgado-Iribarren (1996).

7 Intervención de la senadora del PP Sra. Vindel López el 10 de octubre de 1995 (Delgado-Iribarren, 1996: 2135). 
sibilidad legal de que una prostituta fuera violada; el partido conservador negó esta acusación ${ }^{8}$.

El nuevo Código Penal fue aprobado por la Ley Orgánica 10/1995, de 23 de noviembre, con los votos de todos los parlamentarios salvo los del PP, quienes se abstuvieron por razones ajenas al tratamiento de la prostitución. Los artículos sobre la materia del proyecto presentado en 1994 fueron incorporados a la versión definitiva del Código sin apenas modificaciones.

\section{El contenido de la reforma y las reivindicaciones feministas}

En general, y con algunas excepciones, la prostitución ha constituido una cuestión de baja prioridad para el movimiento organizado de mujeres en su conjunto durante la España postfranquista. A diferencia de otros casos, por ejemplo los Países Bajos (Outshoorn, 1998, 2001a, 2001b), las integrantes de este movimiento (examinado en su totalidad) han debatido muy poco sobre el asunto hasta la conclusión de los años ochenta, y quizá algo más desde entonces.

Hasta finales de la década de los ochenta, la mayor parte de las integrantes de la rama feminista del movimiento concebían la prostitución como una forma extrema de explotación de las mujeres, que minaba el estatus de todas ellas (la ejercieran o no). La meta a largo plazo consistía, pues, en terminar con este ataque a la dignidad de las mujeres (Garaizábal, 1991). Esta postura coincide, aproximadamente, con la posición legal abolicionista ${ }^{9}$. En el ámbito internacional, el punto de vista abolicionista ha sido defendido desde diversas (e incluso contrarias) posturas políticas, entre ellas algunas posiciones feministas. Una de estas autoras, Kathleen Barry $(1985,1996)$, ha definido la prostitución como una forma de explotación femenina y de esclavitud (sexual).

El abolicionismo es hoy día apoyado por algunos grupos feministas, siendo el más visible de ellos la Comisión para la Investigación de Malos Tratos a Mujeres. También son abolicionistas ciertas asociaciones de mujeres cuyo cometido principal radica en proporcionar servicios a quienes ejercen la prostitución, tales como la Asociación para la Prevención, Reinserción y Atención a la Mujer Prostituta (APRAMP). Sus miembros no definen el gru-

\footnotetext{
8 Intervenciones del senador del PSOE Sr. García Marqués y de la senadora del PP Sra. Vindel López el 25 de octubre de 1995 (Delgado-Iribarren, 1996: 2401, 2403).

9 Este punto de vista está presente, entre otras fuentes elaboradas por personas y grupos del movimiento feminista, en Miura (1991); Montero (1986); Oliván (1986); Partit Feminista de Catalunya (1986).
} 
po como uno feminista (Rocío Mora Nieto y María Morales Moreno, APRAMP, entrevista personal, Madrid, 4 abril 2002). Cabe, pues, conceptualizar APRAMP como parte de la rama no explícitamente feminista del movimiento. Otras organizaciones caracterizadas por sus integrantes como feministas y que proporcionan los servicios citados defienden igualmente el abolicionismo, por ejemplo, el Instituto para la Promoción de Servicios Sociales Especializados (IPSSE) (Helena Barea, IPSSE, entrevista personal, Madrid, 8 abril 2002).

Las mujeres prostituidas tradicionalmente han recibido apoyo y servicios por parte de asociaciones religiosas femeninas, entre otras, la Asociación Villa Teresita, la cual ha adoptado asimismo el punto de vista abolicionista (Mercedes Gascue Uranga, Asociación Villa Teresita, entrevista personal, Madrid, 15 abril 2002). Estos grupos no son habitualmente considerados como parte del movimiento organizado de mujeres.

Desde aproximadamente el final de la década de los ochenta, algunas feministas han considerado la existencia de dos clases diferenciadas de prostitutas: quienes ejercen esta actividad libremente y aquellas obligadas por otras personas. Han demandado que el Estado combata la prostitución forzosa, pero no la libre. Estas feministas definen al primer tipo de prostitutas como trabajadoras del sexo, y reivindican que las autoridades las traten como al resto de los trabajadores, por ejemplo, incluyéndolas en el sistema de Seguridad Social (Fórum de Política Feminista, 2001; Garaizábal, 1991; Pineda, 1995: 108-109). El grupo feminista más conocido que defiende este punto de vista es el Colectivo en Defensa de los Derechos de las Prostitutas Hetaira. La reglamentación también ha sido reivindicada por algunas mujeres que ejercen esta actividad (Concepción García Altares, Colectivo en Defensa de los Derechos de las Prostitutas Hetaira, entrevista personal, Madrid, 30 abril 2002; Olga-Prostituta de Madrid, 1986). Esta posición coincide con la postura legal que apoya la reglamentación estatal de la prostitución (llamada en algunos contextos «reglamentarista»). En la arena internacional, el reglamentarismo, al igual que el abolicionismo, ha sido defendido desde múltiples posturas políticas, además de por un sector del feminismo. Éste lo ha reivindicado utilizando variados argumentos, entre otros, que la prostitución constituye una opción escogida por algunas mujeres que debe respetarse, puesto que están ejerciendo el derecho a disponer de su propio cuerpo, que el Estado no debe prohibir comportamientos sexuales libremente consentidos, que vender trabajo (por ejemplo, manual o mental) o servicios sexuales constituyen actividades similares, si se adopta la premisa de que la sexualidad no constituye una esfera radicalmente diferente de otras dimensiones de la existencia humana, y que, como el resto de los trabajadores, las prostitutas se beneficiarían de la sindicación y un entorno laboral saludable y seguro (Alexander, 1998; Bell, 1994; Chapkis, Posener y Sprinkle, 1995; Jennes, 1990; Pethersen, 1996; Zatz, 1997). 
Es importante destacar que no todas las organizaciones activas en materia de prostitución en España son abolicionistas o reglamentaristas. Algunas asociaciones no han tomado ninguna postura, y sus miembros mantienen opiniones diferentes e incluso contrarias sobre la cuestión. Éste es el caso de algunos grupos religiosos femeninos, tales como el Proyecto Esperanza, que proporciona alojamiento y apoyos varios a mujeres traficadas en España y obligadas a prostituirse, gestionado por la Congregación de Religiosas Adoratrices (Aurelia Agredano Pérez, Proyecto Esperanza, entrevista personal, Madrid, 11 mayo 2002). Lo mismo sucede con Cáritas, la principal organización benéfica católica, compuesta por personas de ambos sexos (Francisco Cristóbal Rincón, Cáritas, entrevista personal, Madrid, 26 abril 2002).

El contenido del Código Penal de 1995 coincide con los objetivos de la rama del movimiento de mujeres que reivindica la reglamentación, pero sólo hasta cierto punto. La postura de las militantes y las líderes de este sector (pero no del abolicionista) es consistente con la despenalización de los comportamientos relacionados con la prostitución realizada en 1995 y con la distinción entre la prostitución forzada y la modalidad libre ${ }^{10}$. Por contraste, quienes defienden el abolicionismo entienden que la prostitución casi nunca o nunca es una actividad ejecutada libremente, por lo que rechazan de forma tajante la diferenciación entre la variedad libre y la obligada. Proponen que el Estado luche activamente por erradicar cualquier tipo de prostitución, en vez de centrar sus esfuerzos en el combate contra uno de sus tipos, cuya misma existencia no reconocen. La supresión de la Ley sobre peligrosidad y rehabilitación social de 1970 es coherente tanto con la reglamentación como con el abolicionismo.

Las representantes del movimiento organizado de mujeres no participaron directamente en el escaso debate parlamentario que precedió a las medidas sobre la prostitución incluidas en el Código Penal de 1995. Ello no obstante, algunos grupos sí trataron, sin éxito, de introducir ideas y propuestas en la deliberación. Por ejemplo, en 1995 miembros de la Comisión para la Investigación de Malos Tratos a Mujeres (grupo feminista abolicionista) presentaron en el Congreso de los Diputados un informe sobre las medidas antiabolicionistas contenidas en el proyecto del nuevo Código Penal (Mujeres, 18, segundo trimestre 1995, p. 17). Junto con otras feministas abolicionistas, también presionaron a algunos parlamentarios socialistas, tratando especialmente de persuadir a las mujeres representantes del PSOE en las Cámaras para que cambiaran los artículos que pretendían despenalizar los comportamientos relativos a la prostitución, tales como organizar esta actividad o lucrarse con ella (Rosario Carracedo Bullido, Comisión para la Investigación de Malos Tratos a Mu-

\footnotetext{
10 La similitud entre algunas de las modificaciones legales de 1995 y ciertos objetivos de la sección del movimiento de muje-
} res favorable a la reglamentación ha sido señalada, entre otros lugares, en Garaizábal (1991: 10). 
jeres, entrevista personal, Madrid, 26 marzo 2002). En 1994 y 1995 esta Comisión organizó conferencias públicas acerca de la materia, a fin de despertar conciencia pública contra el cambio legal que se avecinaba. Para organizar estas charlas contó con la ayuda económica del Instituto de la Mujer (Instituto de la Mujer, 1996b: 226-227).

En síntesis, el nuevo Código Penal de 1995 contenía algunos (pero no la totalidad ni la mayoría) de los objetivos del sector del movimiento organizado de mujeres a favor de la reglamentación, e iba nítidamente en contra de los de la rama abolicionista. Las representantes de ambos sectores de dicho movimiento no participaron directamente en el debate previo a tal reforma legislativa.

Por lo que respecta al feminismo oficial, en términos generales, la prostitución ha constituido un tema de escasa prioridad para el Instituto de la Mujer ${ }^{11}$. La posición y los objetivos del IM tendían a coincidir con los del sector abolicionista del movimiento de mujeres. Esta convergencia se reflejó en el Primer Plan de Igualdad de Oportunidades para las Mujeres $(1988-1990)^{12}$. Dicho Plan con cierta frecuencia mencionaba la cuestión y adoptaba la perspectiva abolicionista. Por ejemplo, afirmaba que, «en términos generales, [la prostitución] no es una opción de vida libremente elegida y conduce a quien la ejerce a una situación límite de explotación a nivel psicológico, social y económico» (Instituto de la Mujer, 1988b: 33). El documento proponía una meta general en este área de política pública: «la necesidad de implantar aquellos mecanismos que posibiliten: 1) una clara lucha contra el proxenetismo (...) [y] 2) una atención decidida a favor de quienes ejercen la prostitución con objeto de lograr que estas personas disfruten de condiciones de vida normales y, sobre todo, para posibilitar el libre abandono de su situación» (Instituto de la Mujer, 1988b: 33). Como objetivos concretos de intervención estatal, establecía dos: «[una] Reforma del Código Penal que acentúe la incriminación de las conductas de explotación de la prostitución de menores de dieciocho años», y la «derogación expresa de la Ley de Peligrosidad y Rehabilitación Social en lo que atañe al ejercicio de la prostitución» (Instituto de la Mujer, 1988b: 34). A diferencia del Primer Plan de Igualdad, el Segundo contenía muy pocas re-

\footnotetext{
11 Esta baja prioridad se refleja en la cobertura de la materia, modesta pero no despreciable, en dos tipos de fuentes: la publicación periódica del IM titulada Mujeres y las Memorias de actividades del IM. He consultado todos los números de Mujeres publicados entre 1983 (primer año de publicación) y 1996 (la revista se interrumpió entre 1986 y 1990), así como las Memorias aparecidas entre 1986 (la primera Memoria) y 1996 (Instituto de la Mujer, 1986, 1988a, 1989, 1990a, 1991, 1992, 1993a, 1994, 1995, 1996a).

12 Un Plan de Igualdad es un instrumento de política pública. Consiste en un conjunto de medidas cuyo objetivo es la consecución de mayores cotas de equiparación entre ambos géneros. Estas medidas son puestas en práctica por los distintos Ministerios en un período determinado. Se han elaborado tres Planes de Igualdad en el Estado central (Instituto de la Mujer, 1988b, 1993b, 1997), para ser aplicados en 1988-1990, 1993-1995 y 1997-2000. Los Planes se preparan conjuntamente por el Instituto de la Mujer y los Ministerios que los llevan a cabo. Una vez que concluye el período de puesta en práctica, su ejecución es evaluada por el IM (Instituto de la Mujer, 1990b, 1996b).
} 
ferencias a la prostitución y no proponía ninguna reforma legislativa en esta materia (Instituto de la Mujer, 1993b).

Como he mencionado, el nuevo Código Penal estableció reformas claramente antiabolicionistas: la despenalización de algunos comportamientos relacionados con esta actividad, tales como promocionar y organizar la ajena y lucrarse con ella, y la distinción (implícita) entre prostitución libre y forzosa. De un modo opuesto, la posición del IM era básicamente abolicionista (de acuerdo con sus documentos públicos). Por tanto, los aspectos antiabolicionistas de la reforma de 1995 no pudieron haberse originado en el Instituto.

Las dos propuestas legislativas del Primer Plan de Igualdad (la intensificación de la lucha contra la prostitución de menores y la supresión de la Ley de peligrosidad y rehabilitación social de 1970) se consiguieron con el Código Penal de 1995. Ello no obstante, el nuevo Código se aprobó muy tarde en relación con el Primer Plan de Igualdad, ya que habían transcurrido cinco años después de la terminación de la aplicación de dicho Plan (1990). Este retraso, y el hecho de que el Segundo Plan de Igualdad, ya entonces en su tercer y último año de ejecución, no contuviera ninguna de las mencionadas dos propuestas, sugieren que el Instituto de la Mujer no ejerció una influencia considerable en la inclusión de las dos modificaciones legislativas citadas en la aprobación de la nueva norma en 1995. Concluyo, pues, que el Instituto no fue capaz de insertar sus preferencias ni definiciones del problema de la prostitución de manera significativa en la deliberación que precedió a la gestación del Código de 1995.

\section{Las nociones de género en el debate}

En 1995 y años anteriores, los discursos elaborados por los grupos de mujeres activos en materia de prostitución solían contener, en grados varios, nociones de género. Esta afirmación es válida para las asociaciones abolicionistas y las reglamentaristas, así como para las que no se habían decantado por ninguna de las dos opciones. Por ejemplo, los documentos producidos por este movimiento asociativo utilizaban expresiones femeninas para referirse a quienes ejercían la prostitución (tales como «las prostitutas» o «las mujeres prostituidas») y masculinas para nombrar a quienes compraban estos servicios sexuales, organizaban o se lucraban de la prostitución ajena (entre otras, «los clientes», los «proxenetas» y «los chulos»). En ocasiones ligaban la cuestión de la prostitución con asuntos más amplios relativos al género; así, mencionaban las diferencias entre la sexualidad masculina (que en algunos casos incluye el intercambio de placer sexual por dinero) y la femenina (que casi nunca comprende esta dimensión). Al igual que sucedía en los escritos del movimiento organizado de mujeres, el lenguaje utilizado en los del Instituto de la Mujer sobre este asunto solía incluir referencias de género. 
A modo contrario, en el (escaso) debate parlamentario sobre la prostitución que precedió la aprobación del Código Penal de 1995 no se usó noción alguna de género. Los participantes no mencionaron a las mujeres o a los hombres explícitamente. En esta deliberación pública, las referencias a la prostitución, a quienes la ejercían o a las personas que organizaban esta actividad o se beneficiaban económicamente de ella, se hicieron en términos muy generales y abstractos, sin explicitar el sexo de los individuos en cuestión. La misma afirmación sirve para caracterizar el lenguaje de la parte del Código Penal de 1995 relativa a la prostitución. Por tanto, las menciones al género usadas en el movimiento de mujeres y el organismo de igualdad no consiguieron formar parte de la deliberación en las Cortes.

\section{DEBATE 2: LA REFORMA DEL CÓDIGO PENAL DE 1999 (1997-1999)}

\section{El marco general del debate}

El 17 de octubre de 1997, el Partido Popular (PP), en el poder desde 1996, presentó en las Cortes un proyecto de reforma del Título VIII del Libro II, sobre los «Delitos contra la libertad sexual», del Código Penal de 1995. Este preparativo de modificación legislativa se ocupaba de muchos asuntos, por ejemplo, la corrupción de menores o el acoso sexual, aparte de la prostitución. En cuanto a ésta, el documento aumentaba las penas en cuatro casos: el delito de promoción de la prostitución de menores e incapaces; el de prostitución forzada cuando el responsable se aprovechara de su condición de autoridad, agente de ésta o funcionario público; los de prostitución en el caso de ser perpetrados con el objeto de lucro; y cuando quien tuviere bajo su potestad, tutela, guarda o acogimiento a un menor o incapaz que se prostituyera, no tratara por todos los medios de impedir que continuara haciéndolo. El documento, además, definía un nuevo delito, el del tráfico de personas con el propósito de explotarlas sexualmente. También mencionaba explícitamente la frecuencia con que los delitos relacionados con la prostitución iban unidos a la perpetración de agresiones sexuales y abusos a las víctimas. La reforma ampliaba el período de prescripción de los delitos cuando la víctima era menor. Asimismo, incluía una definición de la prostitución: aquellos actos de significado sexual ejecutados con una o más personas a cambio de una recompensa económica o de otro tipo. Finalmente, consideraba delito un comportamiento despenalizado en 1995: la promoción de la prostitución de adultos.

Como había ya sucedido en 1995, el debate parlamentario sobre esta reforma del Código Penal versó sólo marginalmente acerca de la prostitución, puesto que trató, principalmente, otros temas, tales como el nuevo delito de corrupción de menores que el PP quería incluir en el paquete legislativo. La escasa deliberación en las Cortes sobre la materia de este estudio incluyó críticas a la definición de la prostitución contenida en el proyecto. EI PSOE de- 
nunció que dicha definición era tan amplia que englobaría los comportamientos de los clientes. La lectura atenta de la discusión parlamentaria induce a pensar que la penalización de éstos parecía horrorizar a los representantes socialistas. EI PSOE también defendió que cualquier definición de la prostitución había de especificar no sólo que el sexo se intercambia por dinero, sino un elemento de «persistencia, permanencia o habituabilidad»13. Coalición Canaria (CC), el Grupo Mixto y el PSOE mantuvieron que la definición resultaba imprecisa y no contenía el requisito de las relaciones sexuales completas ${ }^{14}$. El Partido Nacionalista Vasco (PNV) insistió en que la prostitución era un concepto conocido por toda persona y, por tanto, perfectamente acuñado: el intercambio de sexo por dinero ${ }^{15}$. Por estas y otras razones, los cuatro actores parlamentarios mencionados reivindicaron la supresión en el proyecto de la definición de la prostitución.

Estas cuatro organizaciones políticas también se opusieron a penalizar la promoción de la prostitución de adultos, utilizando varios argumentos para defender su punto de vista. Si el ejercicio de la prostitución por parte de un adulto no era un delito, tampoco debía serlo la promoción de dicha actividad. Por otra parte, la ley tenía que distinguir entre la modalidad forzada (que habría de perseguir) y la libre (y los comportamientos en torno a esta última, por ejemplo, su promoción), que no debían ser criminalizados, porque pertenecían al ámbito de las conductas privadas de los individuos con capacidad para dar su consentimiento. Además, la penalización de la promoción de la prostitución de adultos implicaría punir algunos comportamientos ampliamente aceptados en la sociedad española, tales como administrar un periódico que publicara anuncios ofertando servicios de prostitución ${ }^{16}$.

Una versión reformada del proyecto original fue presentada en las Cortes y se convirtió en la Ley Orgánica 11/1999, de 30 de abril, de modificación del Título VIII del Libro II del Código Penal aprobado por Ley Orgánica 10/1995, de 23 de noviembre. Era similar al proyecto excepto en cuatro aspectos: no penalizaba la promoción de la prostitución de adultos, no

\footnotetext{
13 Intervención de la diputada del PSOE Sra. Fernández de la Vega (Diario de Sesiones del Congreso de los Diputados, sesión plenaria, sexta legislatura, 12 febrero 1998, p. 7044).

14 Enmienda número 30, de CC, y enmienda número 31, de la Sra. Almeida Castro, del Grupo Mixto (Boletín Oficial de las Cortes Generales - Congreso de los Diputados, sexta legislatura, 16 febrero 1998, Serie A-proyectos, número 89-8, p. 45).

15 Enmienda número 23, presentada por el PNV (Boletín Oficial de las Cortes Generales - Congreso de los Diputados, sexta legislatura, 16 febrero 1998, Serie A-proyectos, número 89-9, p. 25).

16 Intervenciones de la diputada del PSOE Sra. Fernández de la Vega y del diputado de CC Sr. Mardones Sevilla (Diario de Sesiones del Congreso de los Diputados, sesión plenaria, sexta legislatura, 12 febrero 1998, pp. 1044, 1049); Enmienda número 17, presentada por el PNV (Boletín Oficial de las Cortes Generales - Congreso de los Diputados, sexta legislatura, 16 febrero 1998, Serie A-proyectos, número 89-8, p. 23); Enmienda número 31, presentada por la diputada Sra. Almeida Castro, del Grupo Mixto (Boletín Oficial de las Cortes Generales - Congreso de los Diputados, sexta legislatura, 16 febrero 1998, Serie Aproyectos, número $89-8$, p. 27).
} 
definía la prostitución, no incrementaba las penas cuando los delitos relativos a la prostitución eran perpetrados con ánimo de lucro, y sí lo hacía cuando eran cometidos por organizaciones criminales.

\section{El contenido de la reforma y las reivindicaciones feministas}

Dado el escaso lapso temporal entre la elaboración del Código Penal (1995) y la reforma del Título VIII del Libro II (1999), las posiciones sobre la prostitución de las diversas asociaciones y militantes del movimiento de mujeres apenas habían variado. Ello no obstante, sí había aumentado (débilmente) el de todos modos muy escaso número de grupos y personas activas en torno a la cuestión. El contenido de la reforma de 1999 en parte coincidía con algunas (pero no la mayoría) de las metas de dicho movimiento. La postura de la mayor parte de sus militantes (tanto abolicionistas como reglamentaristas, así como quienes no se habían decantado por ninguna de estas dos opciones) no era contraria a la definición del nuevo delito introducido por la reforma de 1999: el tráfico de personas con el objetivo de explotarlas sexualmente. Tampoco era opuesta a la intensificación de la lucha contra la prostitución de menores, ni al celo especial con que el Estado perseguiría y castigaría los delitos contra la prostitución cometidos por organizaciones criminales, ni al aumento de las penas de los delitos relativos a la prostitución cuando quienes los cometieran lo hicieran prevaliéndose de su condición de autoridad, agente de ésta o funcionario público. De acuerdo con los puntos de vista de la mayoría de las líderes y activistas, estas medidas, bien se encaminaban en la dirección adecuada, bien terminarían siendo poco efectivas, pero no eran negativas o contrarias a las que debían adoptarse.

No obstante lo anterior, la similitud entre el contenido de la reforma de 1999 y algunos objetivos del movimiento organizado de mujeres no debe ser sobrestimada, puesto que la mayoría de las reivindicaciones del movimiento no fueron satisfechas con esta modificación legislativa. La rama abolicionista defendía la reinstauración de las leyes abolicionistas, mientras que la Ley de 1999 no supuso ningún avance en este sentido. La rama partidaria de la regulación demandaba que el Estado conceptualizara a las prostitutas como trabajadoras del sexo y que reconociera sus derechos laborales (por ejemplo, a recibir pensiones de jubilación) y sus obligaciones (tales como cotizar a la Seguridad Social). Tampoco dio ningún paso en esta línea la Ley de 1999.

Al igual que en el caso de la elaboración del Código Penal de 1995, en el debate que precedió a su reforma en 1999 las representantes del movimiento organizado de mujeres no tomaron parte, como tales, en la deliberación parlamentaria. Sin embargo, sí lo hicieron algunas diputadas con conexiones con la rama feminista del movimiento y/o que se habían 
definido en público en alguna o numerosas ocasiones como feministas. Éste fue el caso de la diputada por el PSOE María Teresa Fernández de la Vega o de Cristina Almeida Castro, de Izquierda Unida (IU).

En suma, concluyo (con reservas) que la reforma de 1999 coincidía con parte (pero no la totalidad ni la mayoría) de las reivindicaciones del movimiento asociativo de mujeres. Además, personas próximas al mismo y/o que públicamente habían manifestado que defendían ideales feministas participaron directamente en el debate parlamentario previo a la aprobación de la Ley Orgánica 11/1999, de 30 de abril.

Por lo que respecta al feminismo institucional, el Tercer Plan de Igualdad (1997-2000) prestaba una atención moderada a la cuestión de la prostitución: menor que el Primer Plan pero algo mayor que el Segundo. El Tercer Plan explícitamente mencionaba el grave problema de las mujeres y las niñas traficadas y obligadas a ejercer la prostitución. En esta y otras circunstancias, las mujeres no podían disfrutar de los mismos derechos que los hombres. Se afirmaba que las traficadas se encontraban en una posición extremadamente vulnerable que las convertía en víctimas potenciales de violencia física. Como objetivo en este área de política pública, el Plan recomendaba, en términos muy generales, la adopción de medidas para eliminar el tráfico de mujeres efectuado a fin de explotarlas sexualmente (Instituto de la Mujer, 1997: 73-74, 78).

La definición del delito del tráfico de personas con el propósito de su explotación sexual establecida por la reforma del Código Penal de 1999 era similar a los objetivos generales relativos a la prostitución en el Tercer Plan. No sucedía así con el resto de las medidas sobre la materia incluidas en el cambio legislativo de 1999. Por tanto, la coincidencia entre el contenido de la Ley de 1999 y las demandas del IM existió, pero resultó muy limitada. De los documentos públicos del IM cabe deducir que el Instituto no fue el actor principal que estableció la agenda del cambio legislativo, ni quien fijó el contenido ni el tono de la revisión legal de 1999. Es importante añadir que el propósito esgrimido en el Tercer Plan de luchar contra el tráfico de mujeres para su explotación sexual no se oponía a las posiciones mayoritarias del movimiento organizado de mujeres, por lo que, en este caso, pero sólo en éste, los objetivos del Instituto y el movimiento confluyeron, ya que el IM no mencionaba el resto de las metas del movimiento.

Las nociones de género en el debate

Como sucedió en el primero de los debates analizados en este artículo, el discurso elaborado por los grupos de mujeres y por el Instituto incluía menciones al género. Por ejemplo, 
el Tercer Plan de Igualdad trataba la prostitución en la sección sobre la violencia contra las mujeres, relacionando ambos fenómenos.

Por contraste, la deliberación parlamentaria previa a la aprobación de la Ley de 1999, así como la Ley misma, no contenían ninguna noción de género ni referencia alguna a las mujeres. Un lenguaje neutro desde el punto de vista de género fue utilizado a lo largo de toda la discusión. Por tanto, de nuevo, la perspectiva de género con que se debatía en una parte de la sociedad (el movimiento asociativo de mujeres) y del Estado (el IM) no consiguió franquear el umbral parlamentario.

\section{DEBATE 3: LA LEY DE EXTRANJERÍA DE ENERO DE 2000 (1998-2000)}

\section{El marco general del debate}

En febrero y marzo de 1998, IU, Convergència i Unió y el Grupo Mixto presentaron en las Cortes tres proyectos de una nueva Ley de extranjería. La entonces en vigor, que databa de 1985, era considerada obsoleta por varios actores políticos y sociales, ya que, en su opinión, no respondía al reciente fenómeno de la llegada de un número cada vez más elevado de inmigrantes a España. Ninguno de los tres proyectos contenía referencia alguna a la prostitución. El 18 de noviembre del mismo año el PP presentó una enmienda a los tres, según la cual los inmigrantes ilegales que hubieran sido traficados en España y forzados a ejercer la prostitución no serían expulsados en dos circunstancias: si denunciaban a sus traficantes o si cooperaban con las autoridades públicas en la persecución de quienes les habían traficado, proporcionando información relevante o testificando contra ellos. Estos inmigrantes ilegales podrían optar entre volver a sus países de origen o permanecer en España con permisos de residencia y trabajo.

El debate parlamentario que precedió a la aprobación de la Ley de extranjería de 2000 no contuvo referencias a la prostitución. En el que se estableció fuera de las Cortes sólo se mencionó raramente y de pasada el asunto. No tengo conocimiento de que ningún actor político y social de importancia se opusiera a la enmienda sobre personas traficadas y prostituidas presentada por el PP. Esta ausencia de deliberación y de contienda puede ser interpretada de dos formas. De un lado, tal vez refleje el desconocimiento de las organizaciones políticas y sociales acerca del fenómeno del tráfico de personas para su prostitución forzosa o sobre la enmienda del PP. De otro lado, quizá indique la existencia de un consenso entre los principales actores políticos y sociales acerca de la gravedad del problema planteado por un número elevado de inmigrantes sometidos a este tipo de explotación, y respecto a la reducidísima probabilidad de que estas víctimas denunciaran a sus trafican- 
tes a menos que se establecieran poderosos incentivos para que lo hicieran, puesto que los traficantes controlaban estrictamente (y aterrorizaban) a estas mujeres en España y a sus familias en sus países de origen.

El 4 de noviembre de 1999 los tres proyectos se unificaron en otro, que contenía la enmienda sobre individuos traficados y obligados a prostituirse presentada por el PP. El nuevo proyecto se convirtió en la Ley Orgánica 4/2000, de 11 de enero, sobre derechos y libertades de los extranjeros en España y su integración social. El artículo 55 de esta Ley recogía la enmienda sobre prostitución presentada por el partido en el gobierno ${ }^{17}$.

\section{El contenido de la reforma y las reivindicaciones feministas}

La postura de la mayor parte de los grupos activos en torno a la prostitución (abolicionistas, reglamentaristas o neutros respecto a tal disyuntiva) no era contraria a la concesión de derechos de ciudadanía a las personas traficadas y explotadas sexualmente de manera forzosa que denunciaran a sus traficantes o colaboraran con las autoridades en su persecución. Ello no obstante, éste fue el único punto de solapamiento entre las perspectivas del movimiento y la Ley de extranjería. Las militantes del movimiento de mujeres no participaron directamente en el debate parlamentario que precedió a la aprobación del artículo 55 de la Ley de extranjería.

Es preciso advertir que algunos miembros de grupos feministas abolicionistas critican el cambio de énfasis en la política de la prostitución que han supuesto las reformas de los debates dos y tres examinados en este artículo: de la lucha contra ésta se ha pasado al combate contra el tráfico de personas posteriormente explotadas sexualmente. Estas partidarias del abolicionismo condenan sin reservas el tráfico de personas con fines de explotación sexual, pero entienden que las modificaciones legislativas de 1999 y de 2000 indirectamente favorecen la postura reglamentarista por dos razones. De un lado, el debate sobre el tráfico de mujeres obligadas a prostituirse implícitamente sugiere que existen dos formas de prostitución: la libre y la forzada. Esta última modalidad sería la efectuada por las mujeres traficadas, entre otras. Las abolicionistas no están de acuerdo con esta distinción. De otro lado, el acento en la batalla contra el tráfico puede inducir a los ciudadanos a pensar que el principal problema de estas personas radica en que han sido víctimas de tráfico humano, cuando algunas abolicionistas entienden que reside en que son prostituidas (Rosario Carracedo Bullido, Comisión para la Investigación de Malos Tratos a Mujeres, entrevista personal, Madrid, 26 marzo 2002).

17 Esta Ley de extranjería fue modificada por la Ley Orgánica 8/2000, de 22 de diciembre. El artículo 55 de la Ley de enero de 2000 pasó a ser el artículo 59 de la nueva versión de la Ley de diciembre del mismo año. 
En cuanto al feminismo de Estado, el Tercer Plan de Igualdad (1997-2000) comprendía la propuesta 7.3.2, sobre las mujeres que habían sido traficadas en nuestro país y obligadas a prostituirse: «estudiar la viabilidad de establecer un permiso de residencia temporal a las víctimas de tráfico y de explotación de la prostitución que hayan manifestado su disposición a testificar en procesos judiciales» (Instituto de la Mujer, 1997: 79). El IM persuadió a los decisores políticos, sobre todo a los relacionados con el Ministerio del Interior, para que la tuvieran en cuenta y trataran de satisfacerla al elaborar una nueva Ley de extranjería (Dolores Pérez-Herrera Ortiz de Solórzano, Instituto de la Mujer, entrevista personal, Madrid, 19 abril 2002). De hecho, el artículo 55 de dicha Ley no sólo satisfacía lo planteado por la propuesta 7.3.2 del IM, sino que iba mucho más allá. Los legisladores no se limitaron a analizar la posibilidad planteada por el IM, sino que ofrecieron a las personas traficadas y obligadas a prostituirse permisos de residencia y trabajo en determinadas circunstancias.

\section{Las nociones de género en el debate}

Los argumentos sobre la prostitución esgrimidos en el movimiento organizado de mujeres con frecuencia, aunque no siempre, contenían (y contienen) nociones de género, con independencia de que sus militantes apoyen el abolicionismo, la reglamentación o no se decanten por ninguna de estas dos opciones. Ello ha quedado patente en las entrevistas realizadas para esta investigación. Por ejemplo, algunas personas con las que conversé interpretan la prostitución desde una postura abolicionista como una de las manifestaciones extremas de la subordinación de las mujeres; otras, desde el punto de vista reglamentarista, la entienden como una opción profesional (y válida) para las mujeres, dadas las limitadas y deficientes posibilidades laborales de muchas de ellas, debido a múltiples factores, entre otros, a que en el mercado laboral la discriminación por razón de sexo se produce por doquier.

En el mismo sentido, los documentos del IM también utilizan un lenguaje que hace constantes referencias al género cuando tratan el tema del tráfico de inmigrantes para su explotación sexual. Estos escritos con frecuencia se refieren a las «mujeres» traficadas en vez de a los «inmigrantes» o a las «personas», y ligan el asunto de su tráfico a los fenómenos más amplios de la violencia contra las mujeres y la comercialización de sus cuerpos y su sexualidad (por ejemplo, Dávila, 2001: 22-23).

Por contraste, en general, las referencias a la prostitución en la deliberación política en torno a la Ley de extranjería (generada en la arena pública extraparlamentaria) se barajaron en un lenguaje neutral en términos de género. Los participantes en esta discusión tendían a hablar de «extranjeros» o «inmigrantes» traficados, en vez de «mujeres traficadas». Lo 
mismo sucedía en el caso de las menciones a las personas traficadas y prostituidas de la Ley de extranjería de enero de 2000.

\section{DISCUSIÓN DE LOS RESULTADOS}

La similitud entre el contenido de las principales políticas de prostitución en la España postfranquista y las reivindicaciones sobre este asunto planteadas por el movimiento organizado de mujeres ha resultado muy modesta. El presente artículo ha documentado la persistencia de esta pauta con independencia del color político del partido en el gobierno, pues ha caracterizado tanto el mandato socialista como el popular. En algunas cuestiones no ha existido en puridad una coincidencia entre las medidas gubernamentales y las demandas de las organizaciones de mujeres. Más bien los gobernantes han tomado ciertas decisiones que no contradecían las posiciones generales adoptadas por las asociaciones activas en materia de prostitución, pero que tampoco habían reivindicado explícitamente y con intensidad. Además, esta reducida convergencia entre algunas medidas adoptadas y ciertos objetivos de algún grupo de mujeres ha de ser interpretada con suma cautela. La parte del movimiento que trata la prostitución se encuentra desde finales de los años ochenta profundamente dividida. Distintas organizaciones y personas han defendido posturas radicalmente diferentes: el abolicionismo, la reglamentación o ninguna de las dos. Por tanto, con la posible excepción de la prohibición de la prostitución, cualquier decisión adoptada por el Estado coincidirá ineluctablemente con alguna meta planteada por algún grupo de mujeres en la sociedad.

La rama abolicionista del movimiento ha asistido durante los años noventa al rechazo por parte de los legisladores de los compromisos abolicionistas, ya que el Código Penal de 1995 despenalizó los comportamientos asociados a la prostitución que anteriormente constituían delitos, por ejemplo, organizar esta actividad o lucrarse con ella. Las autoridades tomaron estas decisiones toda vez que España continuaba suscribiendo la Convención para la Represión de la Trata de Personas y de la Prostitución Ajena de Naciones Unidas, de 1949, la cual les impedía adoptar este tipo de medidas (Rosario Carracedo Bullido, Comisión para la Investigación de Malos Tratos a Mujeres, entrevista personal, Madrid, 26 marzo 2002).

El sector reglamentarista tampoco ha visto alcanzadas la mayor parte de sus metas. Cierto es que algunos pasos dados por los gobernantes se encaminan en esta línea, por ejemplo, la despenalización de las acciones relativas a la prostitución, la distinción (si bien implícita) entre la modalidad libre y la forzada, e incluso el énfasis en el combate contra el tráfico de personas para su explotación sexual. Sin embargo, el Estado no ha satisfecho la principal 
reivindicación de las militantes reglamentaristas. A diferencia de otros casos, por ejemplo los Países Bajos (Outshoorn, 1998, 2001a, 2001b) o algunos Estados de Australia (Gorjanicyn, 1998), los decisores políticos españoles no han regulado la prostitución como una profesión (o trabajo del sexo), ni es probable que esto ocurra bajo el mandato del presente Gobierno. El 19 de febrero de 2002 el entonces Ministro de Trabajo y Asuntos Sociales, Juan Carlos Aparicio Pérez, declaraba que «bajo la prostitución se hallan situaciones de violencia, de absoluta falta de libertad de la mujer, de agresiones y vejaciones. No estamos ante una profesión (...), sino ante una de las circunstancias sociales que más propicia la violencia y el tráfico de personas» (El País, 20 febrero 2002, p. 24).

También ha sido reducida (pero no inexistente) la concordancia entre las demandas del Instituto de la Mujer y el contenido de las reformas de 1995, 1999 y 2000. Un Instituto básicamente abolicionista, a juzgar por sus documentos públicos, asistió en 1995 a la aprobación de un Código Penal antiabolicionista. El IM sólo consiguió incluir sus objetivos en una decisión de las estudiadas: el artículo 55 de la Ley de extranjería de enero de 2000. Sin embargo, esta reforma legal es la menos importante de las tres examinadas en esta investigación.

Por lo que respecta a los debates parlamentarios que precedieron a las principales decisiones en materia de prostitución, representantes del movimiento, o personas próximas a él, participaron directamente de manera muy limitada en esta deliberación (sólo en el segundo de los tres debates analizados). De otro lado, tanto el movimiento de mujeres como el feminismo de Estado utilizaron nociones de género en la elaboración de argumentaciones con las que defendieron sus posiciones. Por contraste, ninguna de las discusiones en las Cortes anteriores a las reformas de 1995, 1999 y 2000 contenía este tipo de conceptos. Ni el movimiento ni el organismo de igualdad consiguieron, pues, modificar un ápice en este sentido la deliberación en las Cámaras.

Dos razones pueden explicar esta débil impronta de la movilización a favor de las mujeres en la sociedad y el Estado en el contenido de la política de prostitución y su nula capacidad para insertar nociones de género en el debate parlamentario. Primero, la cuestión ha constituido sólo un tema de escasa (si bien no nula) prioridad para el movimiento en su conjunto y el organismo de igualdad en las últimas décadas. Otros asuntos han absorbido su atención y sus esfuerzos, tales como el acceso de las mujeres al empleo remunerado, el control de su capacidad reproductiva y, sobre todo desde los noventa, la lucha contra la violencia contra las mujeres.

Otros trabajos académicos han analizado el impacto del feminismo societal e institucional en dos áreas de política pública diferentes de las examinadas aquí: la formación ocupacio- 
nal y continua (dirigida a los desempleados y los ocupados, respectivamente) y el aborto, bien como tema principal de investigación (Trujillo Barbadillo, 1999; Valiente Fernández, 2000), bien como objeto de estudio secundario (Barreiro Pérez-Pardo, 1998). Estos análisis han documentado que dichos actores consiguieron dejar una impronta relevante, si bien no tan intensa como hubieran deseado, en la formulación de las decisiones gubernamentales acerca de la interrupción voluntaria del embarazo y prácticamente ninguna respecto a la formación para el mercado de trabajo. El acceso al aborto constituía una demanda prioritaria del movimiento feminista y del feminismo de Estado, al menos hasta la década de los noventa, mientras que lo contrario sucedía con la formación ocupacional y continua. Concluyo entonces, de manera aún provisional y a la espera de estudios futuros, que una condición necesaria (pero no suficiente) para que el movimiento de mujeres y los organismos de igualdad influyan en la gestación de políticas públicas radica en que resulte de capital importancia para ambos la cuestión que se dilucida en la arena pública.

Puede aducirse un segundo factor explicativo del escaso papel desempeñado por el feminismo societal y estatal en la política de la prostitución: las características del foro donde se debatieron y decidieron las principales reformas (las Cortes). Se trata de un espacio con muchas características de los ámbitos políticos cerrados, dado que los trabajos parlamentarios se elaboran siguiendo normas fijas, y donde la participación se limita a los líderes de los principales partidos políticos con representación en las Cámaras. Es, pues, en líneas generales, un medio relativamente poco permeable a la influencia directa de actores exteriores al mismo. Existen diversos conceptos en la literatura de Ciencias Sociales para nombrar este tipo de arenas, tales como los «subsistemas políticos cerrados y estructurados» o los «triángulos de hierro». El caso opuesto estaría representado por las «redes», de configuración un tanto amorfa, en las que no está claramente regulado quién participa y quién no en el proceso de toma de decisiones, ni quién lo controla (Anderson, 1994: 75; Heclo, 1978; Stetson y Mazur, 2002: 12).

\section{CONCLUSIÓN}

El limitado impacto tanto del movimiento de mujeres como del feminismo de Estado en el contenido de la política de la prostitución y los debates en las Cortes previos a las reformas más importantes en esta materia en la España postautoritaria constituye el principal hallazgo empírico de este artículo. Dos factores explicativos dan cuenta de esta modesta influencia: la baja (pero no nula) prioridad otorgada a la cuestión por el feminismo societal e institucional, y la naturaleza relativamente impermeable de la arena parlamentaria a intervenciones de actores externos a este ámbito. 
El escaso ascendiente de dicho movimiento asociativo y del principal organismo de igualdad del Estado central debe interpretarse en el contexto de la exigua deliberación pública acerca de la prostitución en España en el Estado central desde 1975; nunca ha sido un asunto ampliamente discutido por los principales actores políticos y sociales. Las reformas legislativas más importantes en este área siempre han formado parte de cambios legales más amplios que comprendían muchas otras materias: la elaboración de un nuevo Código Penal en 1995, la modificación de dicho Código en 1999 y la adopción de una nueva Ley de extranjería en enero de 2000. Como ha mostrado esta investigación, el debate en torno a la prostitución en las deliberaciones parlamentarias que precedieron a estas tres reformas legislativas resultó escasísimo.

La (poca) discusión acerca de la cuestión en la España postautoritaria ha tenido lugar, sobre todo, en el ámbito municipal. De vez en cuando, los medios de comunicación mencionan la movilización contra la prostitución de algunos residentes en zonas donde se ejerce la modalidad callejera. A corto plazo, las autoridades locales, o no responden a la presión de estos ciudadanos, o lo hacen con algunas declaraciones a los medios, ciertos cambios en la regulación del tráfico (cuando los clientes solicitan los servicios desde los automóviles) y/o la intensificación de la vigilancia policial en la zona, la cual ahuyenta sobre todo a los compradores de servicios sexuales y a algunas de las inmigrantes que ejercen la prostitución y carecen de permisos para vivir y trabajar en nuestro país. Las manifestaciones de los vecinos, los decisores políticos municipales, (a veces) algunos miembros del movimiento de mujeres y, casi nunca, las prostitutas callejeras componen el principal debate sobre la cuestión. Su reflejo en los medios suele tratar de aspectos parciales del asunto, tales como la degradación de determinados barrios y el supuesto ascenso de las tasas de delincuencia en las zonas donde se desarrolla esta actividad. Prácticamente nunca plantea otros interrogantes más amplios, entre otros: ¿Por qué existe la prostitución? ¿Por qué los clientes son fundamentalmente hombres? ¿Cuál es la mejor política posible en esta materia, si es que existe alguna?

Explicar por qué en nuestro país no se ha producido esta discusión pública va más allá de los objetivos de esta investigación. De modo tentativo, sugeriría un factor causal posible (entre otros): el legado del anterior régimen autoritario. La dictadura franquista intervino tanto en el ámbito de la sexualidad de la población, intentando reprimirla (sobre todo la de las mujeres), que muchos ciudadanos y decisores gubernamentales, con relativa independencia de su color político, son en la actualidad renuentes a defender abiertamente toda actuación del Estado que pudiera ser vista como restrictiva, e incluso a debatir públicamente acerca de estos asuntos, considerados ahora por numerosas personas como estrictamente privados. La misma razón podría explicar la cuasi ausencia de debate público en otra materia relacionada con la sexualidad: la pornografía. 
Desde finales de los años noventa, el centro de gravedad de la política de la prostitución ha abandonado la lucha contra esta actividad y se ha centrado en el combate contra el tráfico de personas para su explotación sexual. Es una cuestión abierta si esta nueva atención hacia un aspecto del problema (el tráfico) en vez de otro (la prostitución en sí misma) generará un incremento de la deliberación pública en tiempos venideros, o bien contribuirá a amortiguarla aún más. La respuesta a esta pregunta dependerá, en un grado ciertamente limitado pero no desdeñable, de la medida en que el movimiento de mujeres y los organismos de igualdad, a diferencia del pasado, adopten la prostitución como una de sus prioridades o no lo hagan, como hasta ahora, así como del foro político en el que se tomen las futuras decisiones.

\section{ENTREVISTAS}

Agredano Pérez, Aurelia. Proyecto Esperanza. Madrid, 11 mayo 2002.

Barea, Helena. Instituto para la Promoción de Servicios Sociales Especializados. Madrid, 8 abril 2002.

Carracedo Bullido, Rosario. Comisión para la Investigación de Malos Tratos a Mujeres. Madrid, 26 marzo 2002.

Cristóbal Rincón, Francisco. Coordinador del Área de Acción Social de Cáritas Diocesana de Madrid. Madrid, 26 abril 2002.

García Altares, Concepción. Colectivo en Defensa de los Derechos de las Prostitutas Hetaira. Madrid, 30 abril 2002. Gascue Uranga, Mercedes. Asociación Villa Teresita. Madrid, 15 abril 2002.

Mora Nieto, Rocío, y Morales Moreno, María. Asociación para la Prevención, Reinserción y Atención a la Mujer Prostituta. Madrid, 4 abril 2002.

Pérez-Herrera Ortiz de Solórzano, Dolores. Secretaria General del Instituto de la Mujer. Madrid, 19 abril 2002.

\section{REFERENCIAS}

ALEXANDER, Pricilla (1998): «Sex Work and Health: A Question of Safety in the Workplace», Journal of the American Medical Women's Association, 53, 2: 77-82.

ANDERSON, James E. (1994): Public Policymaking: An Introduction, Boston (Massachusetts): Houghton Mifflin Company.

BANASZAK, Lee Ann (1996): Why Movements Succeed or Fail: Opportunity, Culture, and the Struggle for Woman Suffrage, Princeton: Princeton University Press.

BARREIRO PÉREZ-PARDO, Belén (1998): Democracia y conflicto moral: La política del aborto en Italia y España, Madrid: Instituto Juan March de Estudios e Investigaciones.

BARRY, Kathleen (1985): Female Sexual Slavery, Nueva York: New York University Press.

- (1996): The Prostitution of Sexuality: Global Exploitation of Women, Nueva York: New York University Press. 
BASHEVKIN, Sylvia (1996): «Tough Times in Review: The British Women's Movement During the Thatcher Years», Comparative Political Studies, 28, 4: 525-552.

BECKWITH, Karen (1987): «Response to Feminism in the Italian Parliament: Divorce, Abortion, and Sexual Violence Legislation", en The Women's Movements of the United States and Western Europe: Consciousness, Political Opportunity, and Public Policy, eds. Mary Fainsod Katzenstein y Carol McClurg Mueller, Philadelphia: Temple University Press, pp. 153-171.

BELL, Shannon (1994): Reading, Writing, and Rewriting the Prostitute Body, Bloomington/Indianapolis: Indiana University Press.

Boletín Oficial de las Cortes Generales - Congreso de los Diputados, sexta legislatura, 16 febrero 1998, Serie Aproyectos, números 89-8, 89-9.

BURSTEIN, Paul; EINWOHNER, Rachel L., y HOLLANDER, Jocelyn A. (1995): «The Success of Political Movements: A Bargaining Perspective», en The Politics of Social Protest: Comparative Perspectives on States and Social Movements, eds. J. Craig Jenkins y Bert Klandermans, Londres: UCL Press, pp. 275-295.

CARRACEDO BULLIDO, Rosario (2001): “Legislación penal española», en Simposio internacional sobre prostitución y tráfico de mujeres con fines de explotación sexual, ed. Dirección General de la Mujer de la Comunidad de Madrid, Madrid: Dirección General de la Mujer de la Comunidad de Madrid, pp. 149-159.

CHAPKIS, Wendy; POSENER, Jill, y SPRINKLE, Annie (1995): Live Sex Acts: Women Performing Erotic Labor, Nueva York: Routledge.

COBB, Roger W., y ELDER, Charles (1972): Participation in American Politics: The Dynamics of Agenda-Building, Boston: Allyn and Bacon.

CRENSON, Matthew A. (1971): The Un-Politics of Air Pollution: A Study of Non-Decisionmaking in the Cities, Baltimore y Londres: The Johns Hopkins Press.

DAHLERUP, Drude (1993): «From Movement Protest to State Feminism: The Women's Liberation Movement and Unemployment Policy in Denmark», NORA: Nordic Journal of Women's Studies, 1: 4-20.

DÁVILA, Pilar (2001): «Apertura del simposio», en Simposio internacional sobre prostitución y tráfico de mujeres con fines de explotación sexual, ed. Dirección General de la Mujer de la Comunidad de Madrid, Madrid: Dirección General de la Mujer de la Comunidad de Madrid, pp. 21-26.

DELGADO-IRIBARREN, Manuel (ed.) (1996): Ley Orgánica del Código Penal: Trabajos parlamentarios, Madrid: Cortes Generales.

DERY, David (1984): Problem Definition in Policy Analysis, Lawrence (Kansas): University Press of Kansas.

Diario de Sesiones del Congreso de los Diputados, sesión plenaria, sexta legislatura, 12 febrero 1998.

DUERST-LAHTI, G. (1989). «The Government's Role in Building the Women's Movement», Political Science Quarterly, 104: 246-268.

DURÁN, María Ángeles, y GALLEGO, María Teresa (1986): «The Women’s Movement in Spain and the New Spanish Democracy», en The New Women's Movement: Feminism and Political Power in Europe and the USA, ed. Drude Dahlerup, Londres: Sage, pp. 200-216.

EISENSTEIN, Hester (1991): Gender Shock: Practicing Feminism on Two Continents, Sydney: Allen \& Unwin.

El País, 20 febrero 2002.

ESCARIO, Pilar; ALBERDI, Inés, y LÓPEZ-ACCOTTO, Ana Inés (1996): Lo personal es político: El movimiento feminista en la transición, Madrid: Instituto de la Mujer. 
FEICK, Jürgen (1992): «Comparing Comparative Policy Studies - A Path Towards Integration?», Journal of Public Policy, 12, 3: 257-85.

FERREE, Myra Marx (1991-1992): «Institutionalizing Gender Equality: Feminist Politics and Equality Offices», German Politics and Society, 24-25: 53-64.

FOLGUERA, Pilar (ed.) (1988): El feminismo en España: Dos siglos de historia, Madrid: Fundación Pablo Iglesias.

FÓRUM DE POLÍTICA FEMINISTA (ed.) (1991): Prostitución: Debate y propuestas del movimiento feminista, Madrid: Fórum de Política Feminista.

FRANZWAY, Suzanne; COURT, Dianne, y CONNELL, R. W. (1989): Staking a Claim: Feminism, Bureaucracy and the State, Cambridge: Polity Press.

GAMSON, William A. (1990): The Strategy of Social Protest, Belmont (California): Wadsworth.

GARAIZÁBAL, Cristina (1991): «La prostitución: Un debate abierto», en Prostitución: Debate y propuestas del movimiento feminista, ed. Fórum de Política Feminista, Madrid: Fórum de Política Feminista, pp. 6-10.

GELB, Joyce (1987): «Social Movement "Success": A Comparative Analysis of Feminism in the United States and the United Kingdom", en The Women's Movements of the United States and Western Europe: Consciousness, Political Opportunity, and Public Policy, eds. Mary Fainsod Katzenstein y Carol McClurg Mueller, Philadelphia: Temple University Press, pp. 267-289.

- (1989): Feminism and Politics, Berkeley: University of California Press.

GIUGNI, Marco G. (1998): «Was It Worth the Effort? The Outcomes and Consequences of Social Movements», Annual Review of Sociology, 98: 371-393.

GIUGNI, Marco G.; McADAM, Doug, y TILLY, Charles (eds.) (1990): How Social Movements Matter, Minneapolis: University of Minnesota Press.

GORJANICYN, Katrina (1998): "Sexuality and Work: Contrasting Prostitution Policies in Victoria and Queensland», en Politics of Sexuality: Identity, Gender and Citizenship, eds. Terrell Carver y Véronique Mottier, Londres y Nueva York: Routledge, pp. 180-189.

HARROP, Martin (ed.) (1992): Power and Policy in Liberal Democracies, Cambridge: Cambridge University Press.

HAYWARD, Jack (1991): «The Policy Community Approach to Industrial Policy», en Comparative Political Dynamics: Global Research Perspectives, eds. Dankwart A. Rustow y Kenneth Paul Erickson, Nueva York: Harper Collins, pp. 381-407.

HECLO, Hugh (1978): «Issue Networks and the Executive Establishment», en The New American Political System, ed. Anthony King, Washington, DC: American Enterprise Institute, pp. 87-124.

HEIDENHEIMER, Arnold J.; HECLO, Hugh, y ADAMS, Carolyn Teich (1990): Comparative Public Policy: The Politics of Social Choice in America, Europe and Japan, Nueva York: St. Martin's Press.

HOOD-WILLIAMS, John (1996): “Goodbye to Sex and Gender», The Sociological Review, 44: 1-16.

INSTITUTO DE LA MUJER (1986, 1988a, 1989, 1990a, 1991, 1992, 1993a, 1994, 1995, 1996a): Memorias de actividades, Madrid: Instituto de la Mujer.

- (1988b, 1993b, 1997): Planes de Igualdad de Oportunidades para las Mujeres, Madrid: Instituto de la Mujer. 
INSTITUTO DE LA MUJER (1990b, 1996b): Planes de Igualdad de Oportunidades para las Mujeres: Evalución, Madrid: Instituto de la Mujer.

JENNESS, Valerie (1990): «From Sex as Sin to Sex as Work: COYOTE and the Reorganization of Prostitution as a Social Problem», Social Problems, 37, 3: 403-420.

KAMENITSA, Lynn (1997): «Equality Offices in Eastern Germany: Does Institutional Help Marginalized Groups?», German Politics and Society, 15, 3: 24-43.

KAPLAN, Gisela (1992): Contemporary Western European Feminism, Londres: UCL Press y Allen \& Unwin.

KINGDOM, John W. (1984): Agendas, Alternatives, and Public Policies, Glenview (Illinois) y Londres: Scott, Forest and Company.

MAZUR, Amy G. (2001): Making Democracies Work for Women: State Feminism, Women's Movements, and Job Training Policy, New York: Routledge.

McADAM, Doug; McCARTHY, John D., y ZALD, Mayer N. (1988): «Social Movements», en Handbook of Sociology, ed. Neil Smelser, Beverly Hills (California): Sage, pp. 695-737.

MIURA, Asunción (1991): «Abolicionismo, integración y propuestas sobre la prostitución», en Prostitución: Debate y propuestas del movimiento feminista, ed. Fórum de Política Feminista, Madrid: Fórum de Política Feminista, pp. 11-15.

MONTERO, Justa (1986): «Defendamos a las prostitutas, condenemos la prostitución», ponencia presentada en Encuentros en Carabanchel: Violencia contra las mujeres, Madrid, 22-24 enero.

Mujeres (1983-1986, 1990-1996).

NELSON, Barbara (1984): Making an Issue of Child Abuse: Political Agenda Setting for Social Problems, Chicago y Londres: The University of Chicago Press.

OLGA-PROSTITUTA DE MADRID (1986): «Sobre mis experiencias y vivencias en la prostitución», en Debates sobre la prostitución: Valencia, 16, 17 y 18 enero de 1986, ed. Institut Valencià de la Dona, Valencia: Institut Valencià de la Dona, pp. 75-76.

OLIVÁN, Montserrat (1986): «Sobre la prostitución: ¿Trabajadoras del sexo?», ponencia presentada en Encuentros en Carabanchel: Violencia contra las mujeres, Madrid, 22-24 enero.

OUTSHOORN, Joyce (1997): «The Women's Policy Network in the Netherlands», en Sex Equality Policy in Western Europe, ed. Frances Gardiner, Londres y Nueva York: Routledge, pp. 109-126.

- (1998): «Sexuality and International Commerce: The Traffic in Women and Prostitution Policy in the Netherlands», en Politics of Sexuality: Identity, Gender and Citizenship, eds. Terrell Carver y Véronique Mottier, Londres y Nueva York: Routledge, pp. 190-199.

- (2001a): «Debating Prostitution in Parliament: A Feminist Analysis», The European Journal of Women's Studies, 8, 4: 472-490.

- (2001b): «Regulating Prostitution as Sex Work: The Pioneer Case of the Netherlands», Acta Politica: International Journal of Political Science, 36: 155-179.

PARTIT FEMINISTA DE CATALUNYA (1986): «Prostitución», ponencia presentada en Encuentros en Carabanchel: Violencia contra las mujeres, Madrid, 22-24 enero.

PETHERSEN, Gail (1996): The Prostitution Prism, Amsterdam: Amsterdam University Press.

PINEDA, Empar (1995): «Algunas reflexiones sobre el estado actual del feminismo en España», Género y Sociedad, 3: $95-116$. 
ROCHON, Thomas R., y MAZMANIAN, Daniel A. (1993): «Social Movements and the Policy Process», The Annals of the American Academy, 528: 75-87.

SAWER, Marian (1990): Sisters in Suits: Women and Public Policy in Australia, Sydney: Allen \& Unwin.

SCANLON, Geraldine M. (1976): La Polémica feminista en la España contemporánea (1868-1974), Madrid: Siglo XXI.

- (1990): «El movimiento feminista en España, 1900-1985: Logros y dificultades», en Participación política de las mujeres, ed. Judith Astelarra, Madrid: Centro de Investigaciones Sociológicas y Siglo XXI, pp. 83-100.

SCHATTSCHNEIDER, E. E. (1975 [1960]): The Semisovereign People: A Realist's View of Democracy in America, Hindsdale (Illinois): The Dryden Press.

SCOTT, Joan (1986): «Gender: A Useful Category of Historical Analysis», American Historical Review, 91: $1053-1075$.

STETSON, Dorothy McBride (2001): Abortion Politics, Women's Movements, and the Democratic State, Nueva York: Oxford University Press.

STETSON, Dorothy McBride, y MAZUR, Amy G. (2000): «Women's Movements and the State: Job-Training Policy in France and the United States», Political Research Quarterly, 53, 3: 597-623.

- Research Network on Gender Politics and Research-Project Description/January 2002 (disponible el 1 julio 2002 en www.fau.edu/divdept/schmidt/rngs).

STEWART, Debra W. (1980): «Institutionalization of Female Participation at the Local Level: Commissions on the Status of Women and Agenda-Building», Women and Politics, 1, 1: 37-63.

THRELFALL, Monica (1985): «The Women’s Movement in Spain», New Left Review, 151: 44-73.

- (1996): «Feminist Politics and Social Change in Spain», en Feminist Politics and Social Transformation in the North, ed. Monica Threlfall, Londres y Nueva York: Verso, pp. 115-151.

- (1998): «State Feminism or Party Feminism?: Feminist Politics and the Spanish Institute of Women», The European Journal of Women's Studies, 5, 1: 69-93.

TRUJILLO BARBADILLO, Gracia (1999): «El movimiento feminista como actor político en España: El caso de la aprobación de la Ley de despenalización del aborto de 1985», ponencia presentada en el Congreso de la Asociación Española de Ciencia Política y de la Administración, Granada.

VALIENTE FERNÁNDEZ, Celia (1996): «El feminismo institucional en España: El Instituto de la Mujer, 1983-1994», Revista Internacional de Sociología, 13: 163-204.

- (2000): “Género y ciudadanía: Los organismos de igualdad y el Estado de bienestar en España», en Ciudadanía y democracia, ed. Manuel Pérez Ledesma, Madrid: Editorial Pablo Iglesias, pp. 199-229.

WATSON, Sophie (ed.) (1990): Playing the State: Australian Feminist Interventions, Londres y Nueva York: Verso.

ZATZ, Noah D. (1997): «Sex Work/Sex Act: Law, Labor, and Desire in Constructions of Prostitution», Signs: Journal of Women in Culture and Society, 22, 2: 276-308. 


\section{ABSTRACT}

Ever since the mid sixties the policy adopted towards prostitution in Spain was basically abolitionist, since the legal system did not define the exercise of prostitution as a crime, but considered a great number of other kinds of conduct within this sphere to be so, such as organizing the outside party or gaining money from his/her activity. As from 1995, the central body of the State has decriminalized almost all conduct relating to prostitution, preferring to centre this public policy on the fight against the trafficking of people for their sexual exploitation. This article documents the modest role played by the movement organized by women and by organizations working towards equality in the drawing up of the main legislation regarding prostitution in the post-Franco period, and identifies two reasons for explaining this scanty intervention: weak priority granted to prostitution by social and institutional feminism (taken as a whole) and the low permeability of the parliamentary political arena regarding the influence of external agents.

Key words: Prostitution, Women's Movement, State Feminism, Spain, Politics. 